\title{
Argumentos dos atores processuais nas causas jurídicas sobre saúde no Estado da Bahia, Brasil
}

\author{
Arguments of procedural actors in health judicial cases in the State of Bahia, Brazil
}

Argumentos de actores procesuales en los procesos de salud en el Estado de Bahía, Brasil

Edith Maria Barbosa Ramos ${ }^{1}$

RESUMO: Objetivos: trata o artigo da análise dos argumentos fáticos, principiológicos, econômicos, de gestão pública e processuais nas causas judicias sobre saúde no Estado da Bahia com o objetivo de conhecer os discursos proferidos nas causas sobre saúde do autor, do réu e do juiz. Método: levantamento das decisões judiciais no Tribunal de Justiça da Bahia e leitura das peças processuais correspondentes aos atores processuais selecionados: petição inicial, contestação e sentença nos anos de 2012 e 2013. Resultados: foram encontrados 6.339 processuais em 2012 e 1.149 petições iniciais em 2013. Foram validados 64 processos, com 8 demandas iniciadas e sentenciadas no ano de 2012 e 56 demandas iniciadas e sentenciadas no ano de 2013. Das 64 demandas validadas 62 não obtiveram apoio de qualquer tipo de associação e apenas 2 demandantes receberam apoio de associação. As principais prestações de saúde solicitadas foram: 11 aquisição de medicamentos; 11 exames e 10 vagas em leito de UTI, seguidas de 5 cirurgias; 5 aquisição de produtos de saúde e 5 tratamento de saúde. $O$ argumento mais proeminente foi por questões de gestão. Conclusão: os argumentos mais frequentes foi o da má-gestão da política pública.

Palavras-chave: Judicialização. Argumentos jurídicos. Atores processuais.

ABSTRACT: Objectives: this article deals with the analysis of the factual arguments, principiological, economic, public and procedural management in the judicial cases on health in the State of Bahia in order to know what are the speeches made in the health claims of the author, defendant and judge. Method: Judicial decision-making in the Court of Justice of Bahia and reading of the procedural documents corresponding to the selected procedural actors: initial petition, contestation and sentence in the years 2012 and 2013. Results: 6,339 proceedings were found in 2012 and 1,149 initial petitions in 201364 cases were validated, with 8 lawsuits initiated and sentenced in 2012 and 56 lawsuits initiated and sentenced in 2013. Of the 64 validated lawsuits 62 did not obtain support from any type of association and only 2 applicants received association support. The main health care services requested were: 11 purchase of medicines; 11 exams and 10 vacancies in the ICU bed, followed by 5 surgeries; 5 procurement of health products and 5 treatment of health. The most prominent argument was for management issues. Conclusion: the most frequent arguments were the poor management of public policy.

Keywords: Judiciary. Legal arguments. Related searches

\footnotetext{
${ }_{1}^{1}$ Professora da Faculdade de Direito da UFMA, Doutorado em Direito e Pós-doutorado na Fundação Oswaldo Cruz. Email: edithramosadv@yahoo.com.br
} 
RESUMEN: Objetivos: Este artículo analiza los argumentos de hecho, principiológicos, gestión económica, pública y de procedimiento en las causas judiciales de la salud en el estado de Bahía, con el fin de cumplir con los discursos sobre las causas de salud del autor, el acusado y juez. Método: encuesta de las sentencias del Tribunal de Bahía y leer los escritos correspondientes a los actores procesales seleccionados: la aplicación, la defensa y el juicio en los años 2012 y 2013. Resultados: Se encontraron 6339 procedimiento en 2012 y 1.149 peticiones iniciales en 2013. 64 casos fueron validados con 8 demandas iniciadas y condenados en 2012 a 56 demandas iniciadas y condenados en 2013. de las 64 demandas validadas 62 recibido ningún apoyo de ningún tipo de asociación y sólo 2 demandantes recibieron asociación de apoyo. Los principales servicios de salud solicitados eran 11 la adquisición de medicamentos; 11 pruebas y 10 vacantes en cama de la $\mathrm{UCI}$, seguido de 5 cirugías; 5 compra de productos de salud y cuidado de la salud 5 . El argumento más importante era para las cuestiones de gestión. Conclusión: Los argumentos más frecuentes fue la mala gestión de las políticas públicas.

Palabras-Ilave: La legalización. Argumentos legales. Actores procesales.

\section{Introdução}

O inciso IX do artigo 93 da Constituição Federal de 1988 estabelece que todas as decisões dos órgãos do Poder Judiciário devem ser, obrigatoriamente, fundamentadas, sob pena de nulidade. Por sua vez o inciso II do artigo 489 da Lei no 13.105/15 (CPC) regula que são elementos essenciais a sentença, os fundamentos, em que o juiz resolverá as questões principais que as partes lhe submeterem. Da leitura dos dispositivos mencionados se observa a distinção entre decisão e fundamentação. Para Taruffo (1) "el primer procedimiento implica la formulación de elecciones (cognoscitivas, interpretativas, valorativas); el segundo busca demonstrar que las elecciones realizadas son racionalmente aceptables".

Percebe-se que a decisão é ato discricionário que permite ao juiz fazer uma escolha tendo em consideração as hipóteses contidas na lei. É ato que resolve a lide a partir de critérios lógicos, jurídicos, cognoscitivos e valorativos. A fundamentação é uma exigência da decisão, ou, em outras palavras, é a justificação da decisão através de argumentações lógicas idôneas. Sem fundamentação a decisão se torna arbitrária. Para Taruffo (1) se as decisões forem "desproveídas de todo apoyo legal y fundadas ton sólo en la voluntad de los jueces que la suscriben"2 configuram-se com atos despóticos incompatíveis com o estado

\footnotetext{
2 Se as decisões forem desprovidas de todo o apoio legal e fundadas apenas na vontade dos juízes que as prescrevem são atos despóticos. (Tradução livre das autoras)
} 
democrático de direito. Entende-se que a fundamentação se configura como meio de controle da atuação do juiz em seu poder discricionário.

Silva (2) entende que a lei contemporânea é uma forma de exprimir os conflitos humanos, representa um ponto de partida de dúvidas e incertezas, perante a complexidade e conflitualidade da sociedade moderna, por conseguinte, o sistema normativo em sua amplitude é um produto cultural comprometidos com valores políticos e sociais.

Em conflitos que envolvem a temática da saúde o ato de decidir e sua fundamentação ganham extrema relevância. Desvelar os motivos jurídicos, cognoscitivos e valorativos que permitiram a escolha do magistrado, assim como compreender a justificação da decisão, representam elemento fundamental para a garantia tanto do sistema público de saúde quanto da efetivação os direitos fundamentais.

O presente artigo objetiva demonstrar os motivos jurídicos, cognoscitivos e valorativos que sustentaram as decisões dos magistrados de primeiro grau, contidas em sentenças sobre demandas de saúde, no período de 2012 e 2013, nos estados do Ceará, Rio Grande do Norte e Bahia, bem como analisar a logicidade das fundamentações judiciais.

Deve destacar que para construção da presente pesquisa foram consideradas tão somente demandas individuais, com representação de advogado particular ou defensor público, por fornecimento de medicamentos promovidas em face do ente federativo estatal, na jurisdição da capital do Estado pesquisado.

Uma pesquisa sobre os motivos e fundamentos das decisões judiciais em demandas de saúde pode trazer contribuições no que se refere à problematização de um tema extremamente melindroso na configuração estrutural do Poder Judiciário brasileiro, que se insere na própria constituição da conjuntura da separação e legitimidade dos poderes, ao aprofundar a discussão teórica sobre a realidade cotidiana da atuação dos juízes nos processos individuais, temática incipiente no âmbito jurídico acadêmico, mas que envolve evidente atuação de diversos setores na arena dos direitos humanos, e notadamente, de direitos fundamentais sociais.

Contribui no esforço da busca pela compreensão de como as políticas de saúde são apreendidas, compreendidas e operacionalizadas pelo Judiciário brasileiro, no seio de um modelo pluridimensional, com predomínio de uma tradição conservadora e dogmática do Direito. 
Com a análise dos autos processuais pôde-se identificar os subsídios empíricos e contextuais que justifiquem a proposição desta pesquisa teórica e documental, com a intenção de oferecer instrumentos para uma avaliação ex post. Pretendeu-se, como questão central: a avaliação dos motivos e fundamentos das decisões dos magistrados de primeiro grau em demandas de saúde? Como questões derivadas pôde-se indagar: Quais os fundamentos lógicos idôneos para construção da decisão? Em que medida as decisões estão motivadas por questões jurídicas, cognoscitivas e valorativas? Quais os limites e possibilidades da decisão judicial em âmbito de saúde? As questões propostas objetivaram, portanto, pôr em discussão a questão da formação da decisão judicial em saúde e sua própria legitimidade diante de uma realidade de escassez de recursos e desigualdades sociais.

Entende-se, que a percepção desse processo, na conformação da dinâmica das relações entre os sujeitos e interesses envolvidos na temática estudada, bem como as racionalidades que permeiam as decisões judiciais, constituem tarefa essencial no esforço científico que reside na busca pela sistematização do fenômeno da judicialização da saúde no Brasil e seus efeitos na consecução do ato de decidir.

\section{Metodologia}

Tomou-se como objeto de estudo a compreensão dos contextos, motivos e fundamentos das ações judiciais, em especial, os argumentos presentes nas petições iniciais, contestações e sentenças em matéria de saúde, a partir da qual foi eleito como campo empírico as varas da Fazenda Pública da cidade de Salvador, foi estabelecido como foco de interesse o período 2012-2013. Para contemplar tal objeto de estudo, concentrouse o trabalho na identificação dos sujeitos, na sistematização dos motivos e fundamentos presentes nas decisões judiciais de primeiro grau, bem como nas racionalidades determinantes para construção das referidas decisões. Estabeleceu-se três dimensões para a avaliação, quais sejam:
a) argumentos do autor;
b) argumentos do Estado;
c) elementos de fundamentação que justificaram a decisão do juiz.

Para suprir as necessidades metodológicas e a determinação de balizas teóricas capazes de condensar às múltiplas determinações do fragmento da realidade que compõe 
o campo de investigação apresentado na presente pesquisa definiu-se cinco categorias de análise de argumentos: fáticos, principiológicos, econômicos, de gestão pública e processuais como eixos centrais da análise. Em virtude da complexidade do objeto de estudo, que envolve a construção e justificação de argumentos judiciais na arena da saúde pública, a proposta metodológica compreendeu a "análise de conteúdo" como modalidade de pesquisa adotada.

Entendeu-se análise de conteúdo como um conjunto de técnicas de análises das comunicações, que utiliza procedimentos sistemáticos e objetivos de descrição do conteúdo das mensagens ${ }^{2}$. Para compreensão da realidade proposta categorizou-se separadamente os argumentos apresentados pelos autores, nas petições iniciais, e os argumentos do réu, apresentados nas respectivas contestações. Ao final categorizou-se os fundamentos apresentados pelos juízes nas sentenças de procedência, procedência parcial, improcedência ou extinção dos processos nos autos analisados. O processo de sistematização observou o frequenciamento dos argumentos.

Nos argumentos do autor apresentados nas petições iniciais se identificou quatro categorias de conteúdo: de gestão pública, econômicos, fáticos e principiológico. Entendeuse por argumento de gestão aquele relacionado a eficácia do serviço prestado, o alcance concreto ou não das previsões normativas. O argumento econômico diz respeito às condições financeiras da parte autora em custear a prestação do serviço sem que isso implique comprometimento de sua sobrevivência ou de sua família, por parte do réu entendeu-se as limitações orçamentarias do Estado e a utilização do princípio da reserva do possível. O argumento fático relacionou-se as condições de agravamento da saúde ou mesmo risco de morte do paciente no período de espera da decisão ou da prestação da assistência pelo Poder Público. O argumento principiológico diz respeito ao aos direitos prevista nos na Constituição Federal de 1988. Para análise dos argumentos do réu, incluiuse a categoria processual, compreendido como as técnicas procedimentais previstas na legislação processual.

Como critérios para realização da pesquisa foram considerados os seguintes elementos de inclusão e exclusão:

a) Levantamentos das demandas iniciadas e finalizadas nos anos de 2012 e 2013, considerados a conjugação da petição inicial e sentença de primeiro grau no mesmo 
ano de referência, foram desconsideradas as demandas iniciadas e finalizadas em anos de referência diferentes;

b) Foram consideradas validas, para o efeito da presente pesquisa, exclusivamente as demandas promovidas em face do Estado da Bahia, na jurisdição de Salvador, desconsideradas todas as demandas promovidas nas comarcas do interior;

c) Validou-se apenas as demandas de competência das varas da fazenda pública da capital, excluindo-se demandas das varas da infância e juventude e das varas cíveis.

d) Considerou-se somente as demandas promovidas individualmente, com representação por advogado particular ou defensor público, excluídos as demandas patrocinadas por Núcleos de assistência jurídica ou pelo Ministério Público.

\section{Resultados}

A Procuradoria Geral do Estado da Bahia forneceu lista com 6.339 números de autos processuais, após aplicação dos critérios cronológico da petição inicial, foram identificados 1.090 com petições iniciais do ano de 2012 e 1.149 petições iniciais do ano de 2013. Com aplicação do critério que a sentença seja prolatada no mesmo ano de referência da petição inicial, chegou-se a quantidade de apenas 64 processos validos, com 8 demandas iniciadas e sentenciadas no ano de 2012 e 56 demandas iniciadas e sentenciadas no ano de 2013. Das 64 demandas validadas para a presente pesquisa nenhuma teve autoria coletiva. 37 tinham como autor pessoas do gênero feminino e 27 pessoas do gênero masculino. 62 demandantes não obtiveram apoio de qualquer tipo de associação e apenas 2 demandantes receberam apoio de associação. As principais prestações de saúde solicitadas foram: 11 aquisição de medicamentos; 11 exames e 10 vagas em leito de UTI, seguidas de 5 cirurgias; 5 aquisição de produtos de saúde e 5 tratamento de saúde.

Os principais argumentos utilizados pelos autores das demandas foram agrupados em quatro categorias: de gestão pública, econômicos, fáticos e principiológicos. O argumento de gestão pública foi classificado em quatro classes, quais sejam: negativa ou indisponibilidade de fornecimento do medicamento, insumo ou tratamento (A1); exaurimento da via administrativa sem êxito para resolução da demanda (A2); inexistência de vaga na rede pública para internação em leito de UTI (A3) e a ineficácia do medicamento, insumo ou tratamento disponibilizado pelo SUS (A4). O argumento fático foi identificado em única classe: configuração de risco de agravamento ou risco de morte do paciente (B). Os achados 
demonstram duas classes para o argumento principiológico: garantia do princípio da dignidade da pessoa humana $(\mathrm{C} 1)$ e o direito à saúde com garantia de integralidade (C2). Foram encontradas duas classes da categoria econômica: hipossuficiência do paciente (D1) e o alto custo do medicamento, insumo e tratamento (D2).

Quadro 1 - Categoria e Classe dos Argumentos do Autor dos processos

\begin{tabular}{|l|l|l|}
\hline \multicolumn{1}{|c|}{ Categoria do Argumento } & \multicolumn{1}{c|}{ Classe do Argumento } & \multicolumn{1}{c|}{$\begin{array}{c}\text { Percentual de } \\
\text { utilização }\end{array}$} \\
\hline Gestão Pública & A1, A2, A3 e A4 & $34,97 \%$ \\
\hline Fático & B & $31,69 \%$ \\
\hline Principiológico & C1, C2 & 21,31 \\
\hline Econômico & D1, D2 & $12,02 \%$ \\
\hline
\end{tabular}

Os argumentos do Estado da Bahia (réu), defendidos nas contestações patrocinadas pela Procuradoria do Estado, foram classificados em quatro categorias, quais sejam: econômico, processuais, de gestão pública e principiológico. No interior do argumento econômico identificou-se duas classes: grave lesão à ordem social e econômica (E1) e a orçamento limitado do Estado (E2). Entre os argumentos processuais destacou-se a perda do objeto da ação (F1), ilegitimidade passiva do Estado (F2) e ausência do interesse de agir do autor (F3). Foram encontrados entre os argumentos principiológicos: o princípio da integralidade do sistema (G1) e o princípio da reserva do possível (G2). Como argumentos de gestão pública identificou-se 3 classes: o Estado não tem obrigatoriedade no fornecimento do medicamento, insumo ou tratamento em virtude de não estar padronizado (H1); o paciente deve utilizar a via administrativa em virtude de o medicamento, insumo ou tratamento ser fornecido pelo SUS (H2) e o medicamento, insumo ou tratamento pode ser substituído por outro similar fornecido pelo SUS (H3).

Quadro 2 - Argumentos do Réu nos processos judiciais

\begin{tabular}{|l|l|l|}
\hline \multicolumn{1}{|c|}{ Categoria do Argumento } & \multicolumn{1}{|c|}{ Classe do Argumento } & \multicolumn{1}{|c|}{$\begin{array}{c}\text { Percentual de } \\
\text { utilização }\end{array}$} \\
\hline Econômico & $\mathrm{E} 1, \mathrm{E} 2$ & $40,98 \%$ \\
\hline Processuais & $\mathrm{F} 1, \mathrm{~F} 2, \mathrm{~F} 3$ & $35,25 \%$ \\
\hline Principiológicos & $\mathrm{G} 1, \mathrm{G} 2$ & $13,11 \%$ \\
\hline Gestão Pública & $\mathrm{H} 1, \mathrm{H} 2, \mathrm{H} 3$ & $10,66 \%$ \\
\hline
\end{tabular}


No julgamento das demandas o Poder Judiciário da Bahia decidiu pela procedência de $53,13 \%$ dos casos, pela procedência parcial de 4,69\%, pela improcedência de 37,50\%, extinguiu processo sem resolução do mérito em 1,56\% e decidiu em forma não prevista na legislação em 3,13\%, buscando a mediação entre as partes.

Os fundamentos das decisões judiciais foram classificados em 4 categorias: principiológicos, processuais, fáticos e de gestão pública. Entre os fundamentos principiológicos identificou-se três classes: garantia integral do direito à saúde (J1), direito à saúde como dever do Estado e direito de todos (J2) e o princípio da integralidade (J3). Na categoria de fundamentos fáticos identificou-se duas possibilidades: falecimento do autor (K1) e comprovação da necessidade do pedido (K2). Os achados indicaram duas classes de argumentos da categoria processual: perda do objeto da ação (L1) e falta do interesse de agir (L2). Na categoria de gestão pública identificou-se apenas a classe responsabilidade solidária dos entes federativos (M1).

Quadro 3 - Argumentos do Juiz nos processos judiciais

\begin{tabular}{|l|l|l|}
\hline Categoria do Argumento & Classe do Argumento & $\begin{array}{l}\text { Percentual de } \\
\text { utilização }\end{array}$ \\
\hline Principiológicos & $\mathrm{J} 1, \mathrm{~J} 2, \mathrm{~J} 3$ & $46,75 \%$ \\
\hline Fáticos & $\mathrm{K} 1, \mathrm{~K} 2$ & $35,06 \%$ \\
\hline Fáticos & $\mathrm{L} 1, \mathrm{~L} 2$ & $14,29 \%$ \\
\hline De Gestão Pública & $\mathrm{M} 1$ & $3,90 \%$ \\
\hline
\end{tabular}

\section{Discussão}

Nenhuma das ações analisadas tiveram autoria coletiva, esse dado já foi destacado por Machado (3), que afirmou que os pleitos individuais tiveram mais êxito e notoriedade que ações coletivas, justificam que o Poder Judiciário tem evitado opinar nesse tipo demanda possivelmente porque tais ações incidam diretamente na gestão pública. A maioria das demandas em saúde pública buscou a aquisição de medicamentos, realização de exames e vagas em leito de UTI.

O principal problema apresentado, como argumento do pedido dos autores foi a má gestão dos recursos públicos (materiais, estruturais e humanos). Em decorrência da demora na consecução do acesso ao tratamento, a situação fática de urgência para o atendimento, 
sob pena do agravamento da situação do paciente ou mesmo de sua morte. Constatou-se que, apenas, de forma minoritária os autores argumentaram buscavam um serviço não prestado pelo SUS ou que buscaram a substituição de um medicamento, insumo ou tratamento por considerarem que o disponibilizado pelo SUS era ineficaz.

A maioria dos autores das demandas judiciais considerou, como principal argumento, a necessidade do respeito à dignidade da pessoa humana, independentemente da previsão constitucional do direito à saúde como direito fundamental social. Observou-se, que a maioria dos autores, não considerou o argumento econômico como decisivo para fundamentar o pedido para garantia de prestação do serviço (4), (5), (6). No entanto a judicialização não está dissociada dos interesses econômicos existentes no sistema político, aparecendo os tribunais para os grupos de interesse como um importante órgão de reconhecimento de novos direitos e para os políticos de oposição como um instrumento para frear, obstaculizar e inviabilizar as ações governamentais.

A maior parte dos argumentos apresentados pela Procuradoria do Estado da Bahia, disseram respeito a temática econômica, em especial, questões relacionadas a lesão à ordem econômica e a limitação orçamentária. No entanto, observou-se que esse argumento não coincide com as teses levantadas pelo autor, que em sua maioria solicitam prestações padronizadas e reconhecidas pelo SUS, o que reforça o entendimento de má gestão da política de saúde (3), (7), (8), (9). Além disso, o Estado da Bahia tem, na maioria dos casos, discutido argumentos técnicos e processuais, que, em última análise, objetivam simplesmente obstaculizar ou dificultar o andamento do processo judicial. A tática do réu é fazer com que o processo não chegue a seu fim natural: a sentença. A Procuradoria do Estado não enfrentou ou, simplesmente, ignorou os argumentos da gestão pública e principiológicos da CF/88 e do SUS. Os juízes, via de regra, decidiram pela procedência das demandas e nas fundamentações de suas decisões priorizaram os argumentos principiológicos e fáticos.

\section{Considerações finais}

Apesar dos avanços que foram ensejados pelo SUS, o sistema não vem conseguindo atender de forma satisfatória as demandas sociais pelos mais variados serviços de saúde. Diante da incapacidade de o SUS atender de forma adequada as demandas sociais, vem se fortalecendo cada vez mais o fenômeno da os da saúde, entendido como a transferência 
das decisões de políticas públicas em saúde das instâncias políticas para o Poder Judiciário, que passou a decidir sobre uma série de questões, tais como: fornecimento de medicamentos, tratamentos, órteses e próteses; pedidos de cirurgia e acompanhamento cirúrgico; internações hospitalares e em unidades de terapia intensiva; solicitação de home care e transplantes, dentre outros.

A judicilialização da saúde se tornou, assim, um problema para o Judiciário, não apenas pela grande quantidade de ações em tramitação, mas, sobretudo, em virtude das especificidades e complexidades que giram em torno do tema, as quais vão desde a legitimidade deste Poder para o controle das políticas públicas até a dificuldade da especificação do âmbito de proteção do direito à saúde, as questões orçamentárias e técnicas, dentre outras.

Considera-se legítimo o controle jurisdicional das políticas públicas em saúde, na medida em que o próprio desenho institucional permite tal controle. Frente ao déficit ou carência de políticas públicas, a judicialização é fator imprescindível para a efetivação do direito fundamental à saúde. Todavia, neste campo, o Judiciário tem que agir com cautela, pois tal fenômeno pode abalar a própria estabilidade das instituições democráticas, na medida em que, a partir da judicialização das questões de saúde, o Poder Judiciário é obrigado a se imiscuir nas áreas de alocação de recursos e de prioridades do Estado, às vezes sem estar devidamente preparado para tanto.

Faz-se necessária a disseminação da percepção de que a universalidade do direito não significa que toda e qualquer prestação em saúde requerida pelas partes deva ser atendida, devendo o Poder Judiciário estar preparado para diferenciar aquilo que se refere apenas a um interesse privado da parte e aquilo que de fato está inserido no âmbito de proteção à saúde configurada como prestação obrigatória do Estado.

É preciso haver uma racionalidade na concessão de medidas judiciais em saúde, sendo as diretrizes do SUS estabelecidas na Constituição Federal, na Lei Orgânica da Saúde e demais atos normativos, importantes marcos para a concretização do direito à saúde, para, diante da sua complexidade e multiplicidade de prestações, especificar o âmbito de abrangência do direito, ou pelo menos, aquilo que ele não comporta.

Dessa forma, faz-se necessário observar, por exemplo, que os ditames dos princípios da unidade, descentralização, hierarquia e regionalização do SUS são violados diante de determinadas decisões judiciais, como as que determinam o dispêndio de recursos públicos 
para o custeio de remédios, tratamentos e procedimentos prescritos exclusivamente por profissionais que não pertencem aos quadros do sistema público; as que são proferidas sem a análise minuciosa dos atos normativos de repartição de competência e responsabilidade; e as que condenam os municípios ao fornecimento de serviços de alta complexidade ou bens de alto custo. Assim, tem-se que as diretrizes do SUS e os atos normativos estabelecidos pelo Ministério da Saúde devem ser conhecidos, observados e respeitados pelos magistrados.

O Poder Judiciário precisa reconhecer o fato de que não são é protagonista do processo de implementação de políticas públicas, na medida em que os seus membros, em geral, não são os mais habilitados a produzir a melhor decisão em matéria de saúde, pelo que devem prestigiar as manifestações do Legislativo ou do Executivo, cedendo o passo para juízos discricionários dotados de razoabilidade.

Entende-se, também, que, em um cenário de ausência de políticas públicas, a intervenção do Poder Judiciário deve ser a exceção e não a regra, uma vez que é do Legislativo e do Executivo a competência de, observando os ditames da reserva do possível e sopesando o direito individual em face do direito da coletividade, traçar as políticas públicas e definir as prestações a serem fornecidas.

Diante da ausência ou má gestão de políticas públicas, o Poder Judiciário somente deve agir quando observar que há uma omissão ou uma incapacidade de atuação do Estado em resolver, mediante políticas públicas, questões que ultrapassam a dimensão do interesse individual, não devendo interferir no campo das políticas públicas (diga-se, quando estas forem inexistentes) para tutelar interesse estritamente individuais e pontuais. Deve haver, por trás de uma demanda individual, um problema de ordem coletiva a justificar a atuação ativista do Poder Judiciário. Somente assim, se poderá garantir a possibilidade de o Judiciário não se ver engessado diante de omissões violadoras da Constituição dos Poderes majoritários, ao mesmo tempo em que se pode evitar a intromissão indiscriminada dos magistrados nas searas próprias do Executivo e Legislativo.

\section{Referências}

1. Taruffo, M. El vértice ambíguo - Ensayos sobre la casación civil. Palestra Editores: Lima, 2005 
2.Silva, OAB. Fundamentação das sentenças como garantia constitucional. Disponível em: <http://www.baptistadasilva.com.br/artigos010.htm>. Acesso em: 16 ago 2007.

3.Machado, CV. O papel federal no sistema de saúde brasileiro. In. Fundação Oswaldo Cruz.A saúde no Brasil em 2030 - prospecção estratégica do sistema de saúde brasileiro: organização e gestão do sistema de saúde. Rio de Janeiro: Fiocruz/lpea/Ministério da Saúde/Secretaria de Assuntos Estratégicos da Presidência da República, 2013. Vol. 3. 3570 pp. ISBN 978-85-8110-017-3. Disponível em: <http://books.scielo.org/id/98kjw/pdf/noronha-9788581100173-04.pdf> Acesso em 20 maio 2016

4.Ventura, M; Simas, L; Pepe, VLE ; Schramm, FR. .Judicialização da saúde, acesso à justiça e a efetividade do direito à saúde. Physis 20 (1):77-100. Disponível em; <http://www.scielo.br/scielo.php?script=sci_arttext\&pid=S0103-73312010000100006> Acesso em 8 dez 2015.

5.Pepe, VLE et al. A judicialização da saúde e os novos desafios da gestão da assistência farmacêutica. Ciênc. saúde coletiva 15(5): 2405-2414, 2010. Disponível em: http://www.scielo.br/scielo.php?script=sci_arttext\&pid=S1413-81232010000500015 Acesso em: 10 de jan 2016.

6.Ramos, EMBR. Universalidade do Direito à Saúde. São Luiz, EDUFMA. 2014

7.Paim, JS; Teixeira, CF. Configuração institucional e gestão do Sistema Único de Saúde: problemas e desafios.Ciênc. saúde coletiva 12:1819-1829, 2007. Disponível em: <http://www.scielo.br/scielo.php?script=sci_arttext\&pid=S1413-81232007000700005> Acesso em 13 mar 2016.

8.Costa, AM.; Vieira, NA. Participação e controle social em saúde. In Fundação Oswaldo Cruz. A saúde no Brasil em 2030 - prospecção estratégica do sistema de saúde brasileiro: organização e gestão do sistema de saúde. Rio de Janeiro: Fiocruz/lpea/Ministério da Saúde/Secretaria de Assuntos Estratégicos da Presidência da República, 2013. Vol. 3. pp. 237-271. Disponível em <http://books.scielo.org/id/98kjw/pdf/noronha-978858110017308.pdf> Acesso em 19 abril 2016.

9.Costa, AM, Lionço, T. Democracia e gestão participativa: uma estratégia para a equidade em saúde?.Saude soc. 15(2): 47-55, 2006. Disponível em: <http://www.scielo.br/scielo.php?script=sci_arttext\&pid=S0104-12902006000200006> Acesso em 6 de jan 2016.

Recebido em: 23.jan.2017

Aprovado em: 21.mar.2017

\section{Como citar este artigo:}

Ramos BEM, Delduque MC. Argumentos dos atores processuais nas causas jurídicas sobre saúde no Estado da Bahia, Brasil. Revista Cadernos Ibero-Americanos de Direito Sanitário. 2017 jan./mar, 6(1):127-138. 